\title{
Vorstand der DG PARO in neuer Zusammensetzung
}

Im Vorfeld ihrer Jahrestagung in Würzburg haben die Mitglieder der Deutschen Gesellschaft für Parodontologie (DG PARO) ihren Vorstand neu gewählt. Prof. Dr. Christof Dörfer übernahm turnusgemäß das Amt des Präsidenten. Er wird die nächsten 3 Jahre die Geschäfte des Vorstands der Fachgesellschaft führen. Neu nominiert als Präsidentin elect wurde die bisherige Generalsekretärin PD Dr. Bettina Dannewitz, einstimmig. Damit wird zum 2. Mal in der Geschichte der DG PARO eine geschlechtergemischte Spitze die Interessen der Fachgesellschaft vertreten. Weitere Informationen zur DG PARO und zum neu gewählten Vor-

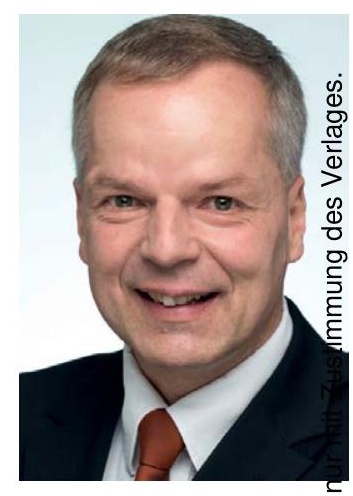

stand unter: http://mitglieder.dgparo.de/ dgparo/vorstand

Nach einer Pressemitteilung der Deutsche Gesellschaft für Parodontologie e.V., Regensburg kontakt@dgparo.de www.dgparo.de 